\title{
Rare Benign Entities of the Breast - Myoid Hamartoma and Capillary Hemangioma
}

\author{
Seltene benigne Entitäten der Mamma - \\ das myoide Hamartom und das kapilläre Hämangion
}

Authors

Affiliations
F. K. Schäfer ${ }^{1}$, J. Biernath-Wuepping ${ }^{1}$, C. Eckmann-Scholz ${ }^{2}$, B. M. Order ${ }^{1}$, M. Mathiak ${ }^{3}$, F. Hilpert ${ }^{2}$, A. Strauss ${ }^{2}$, W. Jonat ${ }^{2}$, P. J. Schäfer ${ }^{1}$

${ }^{1}$ UKSH Campus Kiel, Bereich Mammadiagnostik und Intervention, Kiel

${ }^{2}$ UKSH Campus Kiel, Klinik für Gynäkologie und Geburtshilfe, Kiel

${ }^{3}$ Institut für Pathologie, UKSH Campus Kiel, Kiel

\section{Key words \\ - breast \\ - mammography \\ - ultrasound \\ Schlüsselwörter \\ - Brust \\ - Mammografie \\ - Ultraschall}

\section{Abstract \\ $\nabla$}

Hamartomas can occur in different areas of the breast, but they are rarely found in the breast. Myoid hamartomas with smooth muscle cells of the type described here are particularly unusual. The pathogenesis of this benign entity with its tendency to growth and recurrence is not clear. Excision is the therapy of choice. Capillary hemangiomas are rare vascular malformations of the breast which, in contrast to cavernous hemangiomas, usually remain clinically occult. It is important to differentiate these benign findings from malignant angiosarcoma. The possible heterogeneities between myoid hamartoma and capillary hemangioma using current breast imaging methods for the differential diagnosis (high-resolution ultrasound, duplex sonography, shear wave elastography, digital mammography, minimally invasive intervention) are discussed together with an overview of the literature.

\section{Zusammenfassung \\ $\nabla$}

Hamartome können in unterschiedlichen Körperregionen auftreten, sind in der Brust aber selten. Insbesondere die hier beschriebene Variante eines myoiden Hamartoms, welches glatte Muskelzellen enthält, ist außergewöhnlich. Die Pathogenese des gelegentlich wachstumsprogredienten und rezidivierenden myoiden Hamartoms ist nicht geklärt. Therapie der Wahl stellt die Exzision dar. Zu den raren vaskulären Neubildungen in der Mamma gehören die hier präsentierten kapillären Hämangiome, die klinisch im Gegensatz zu den kavernösen Hämangiomen meist inapparent bleiben. Zu differenzieren sind diese Befunde vom malignen Angiosarkom. In dieser Arbeit werden die möglichen Heterogenitäten des myoiden Hamartoms und der kapillären Hämangiome in der modernen bildgebenden Mammadiagnostik und ihre Differenzialdiagnosen (hochauflösende Sonografie, Duplex-Sonografie, Scherwellenelastografie, digitale Mammografie, minimalinvasive Abklärungsmethoden) zusammen mit einer Literaturübersicht ausführlich diskutiert.

include dorsal acoustic enhancement and typically there is also discrete shadowing around the contour laterally. Popcorn calcifications are pathognomonic for fibroadenomas; these calcifications are clearly visible on mammograms and present as acoustic shadowing on ultrasound. It is important to differentiate such findings from fibroadenolipoma, a benign but extremely rare lesion, which contains fibrous and adenomatous tissue as well as lipomatous parts. Mammography findings are quite heterogeneous and range from radiotranslucent to radioopaque masses with a halo. Phyllodes tumours have a similar imaging morphology to that of fibroadenoma; benign phyllodes tumours in particular bear a histological resemblance to fibroadenoma. Phyllodes tu- 
mours are typically very fast growing; however this may also be the case with juvenile fibroadenomas.

Papilloma is another benign lesion of the breast, which presents on mammography as a dense, usually smooth mass. Sclerosed papillomas include calcifications. Papillomas of the breast are usually located centrally or in the retromammary space, but they can also occur in peripheral locations. Papillomatosis findings consist of several cellular growths in the mammary ducts. The lesions are usually discovered coincidently during mammography or sonography. Yellow-brownish or bloody nipple discharge is very common with papillomatosis, making additional imaging diagnostics using mammography, sonography, galactography or brush cytology necessary.

Galactoceles are also benign lesions of the breast. Galactoceles present a complex radiographic picture on sonography and mammography.

Lipoma is a benign encapsulated tumour composed of adipose tissue and imaging findings are unambiguous. Sonographically, lipomas are characterised by their discrete higher echogenicity compared to surrounding adipose tissue. They are movable and can be easily compressed by the transducer. In contrast to the lesions listed above, lipomas do not require further minimally invasive investigation.

Common benign breast changes include fibrocystic mastopathy and adenosis. Characteristic for these conditions are fibrosing tissue, cystic changes and benign epithelial hyperplasias.

The most frequent breast lesions are cysts, both simple benign mammary cysts and complex cysts. The size of the cyst varies according to the hormonal cycle and can range from a few millimetres to several centimetres. On mammography cysts appear as homogeneous, smooth dense masses, overlaid by parenchymal tissue. Ultrasound findings are pathognomonic, with cysts visualised as smooth, echo-free lesions with increased dorsal echogenicity. Ultrasound is routinely used to differentiate cysts and solid lesions and provides a high degree of diagnostic certainty.

Liponecrosis or oil cysts are benign complex lesions of the breast, visible on mammography as smooth, partly lipomatous, partly dense lesions. The lesions typically calcify over time, and images can show amorphous onionskin-like calcifications. Sonographically, images may show complex echoic patterns, but in combination with mammography, the lesions can be unambiguously identified as liponecrosis. Hamartoma is an equally complex lesion on mammography and sonography. Seromas and lymphoceles are difficult to identify definitively using mammography alone, but they can be adequately characterised using sonography.

Puerperal mastitis is another frequently occurring benign change to the breast. The differential diagnosis is more problematic if the indications suggest non-puerperal mastitis. Non-puerperal mastitis needs to be clearly differentiated from inflammatory carcinoma, dermatological disease or post radiogenic changes. In summary, it must be stated that, while mammography remains the gold standard for diagnosis, sonography is the most important non-invasive imaging procedure for senological diagnosis. Magnetic resonance imaging also plays an important diagnostic role for specific indications and elastography is becoming increasingly important.

When evaluating breast lesions, it is important to factor in the heterogeneous presentation of breast cancer in various imaging procedures when attempting a differential diagnosis.

\section{Introduction to Case 1}

$\nabla$

Hamartomas can occur in many different areas of the body. They are most commonly found in the lungs but also occur subcutaneously, in the hypothalamus, the spleen, or the kidneys. Hamartomas of the breast are rare. They are characterised by the different types of tissue they contain. Myoid hamartoma which contains smooth muscles cells is extremely rare. The pathogenesis of myoid hamartoma has not yet been conclusively established.

In this case report we discuss the mammography and sonography images together with histopathological and immunohistochemical findings for the diagnosis of myoid hamartoma. The relevant clinical and therapeutic aspects are presented.

\section{Description of Case 1}

$\nabla$

We report here on a 50-year-old pre-menopausal woman who was not taking hormonal preparations and who had a familial history of breast cancer diagnosed in her mother at the age of 73. The patient was in good general health and presented for a diagnostic work-up, consisting of punch biopsy, of a focal finding classified externally as BI-RADS 4. Findings on palpation and inspection of both breasts were unremarkable and lymphatic drainage was not impaired.

On control mammography a focal finding in the right breast was noted in the 12 o'clock position at $6 \mathrm{~cm}$ distant from the nipple (classification 6 months earlier was BI-RADS 3, not apparent on sonography). The nodule was a progressively growing (from $0.6 \times 0.5 \mathrm{~cm}$ to $1.0 \times 1.0 \mathrm{~cm}$ ), increasingly dense lesion with $60 \%$ diffuse margin ( $\bullet$ Fig. 1 a and b). Sonography documented a focal lesion with a fuzzy margin, a diameter of $1.0 \times 0.9 \mathrm{~cm}$, a hypoechoic centre measuring $0.5 \times 0.5 \mathrm{~cm}$, and an unusually broad hyperreflexive margin peripherally ( $\bullet$ Fig. $\mathbf{2 a}$ und b). The lesion was classified as BI-RADS 4 and an ultrasound-controlled punch biopsy was performed for assessment.

- Fig. $\mathbf{3}$ a and $\mathbf{b}$ shows the histopathology of a fibroadenoma of the breast ( $\mathrm{H} \& \mathrm{E}$ ) with typical positivity of the myoepithelium for smooth muscle actin (SMA) and negativity of the stroma for SMA, shown here for comparison. In contrast, 0 Fig. $\mathbf{3 c}$ and $\mathbf{d}$ of the case presented here shows the histopathological image of a myoid hamartoma ( $\mathrm{H} \& \mathrm{E}$ ) with a proliferation of stromal nodules composed of interwoven spindle cells, positive for SMA.

\section{Discussion of Case 1}

\section{$\nabla$}

With an incidence of $0.7-4.8 \%$ of all benign breast tumours [1], hamartomas of the breast represent a relatively rare neoplasia of the breast. As a rule they consist of varying combinations of adipose, glandular, and connective tissue which form a smooth, soft to moderately firm, palpable and moveable nodule. Mammography and sonography images are considered pathognomonic (BI-RADS 2), and no further histological assessment is necessary.

Myoid hamartoma is an extremely rare variant of hamartoma. This subtype is characterised histopathologically by the presence of smooth muscle cells. Myoid hamartomas also include adipose, connective and glandular breast tissue. Hematoxylin-eosin staining shows bundles of spindle cells without atypia but with eosinophilic cytoplasm and enlarged nuclei. Immunohistochemistry is helpful for assessment and shows positivity for SMA, desmin and 

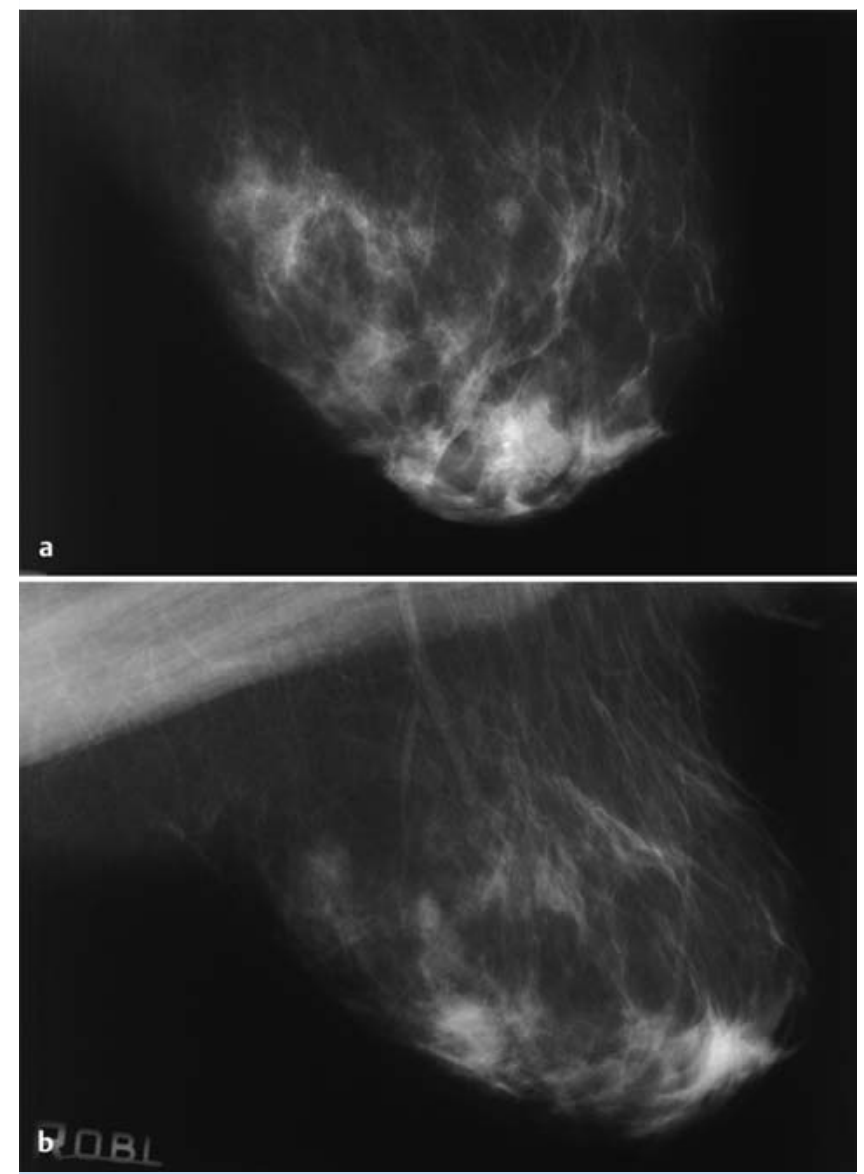

Fig. $1 \mathbf{a}$ and $\mathbf{b}$ Focal finding in the right breast in the 12 o'clock position, $6 \mathrm{~cm}$ from the nipple, with $60 \%$ uncircumscribed margin and a diameter of $1.0 \times 1.0 \mathrm{~cm}$.

vimentin. Immunohistochemistry assessment may show negativity for cytokeratin and S-100 protein. Although myoid hamartomas are classified as benign, a case has been reported in the literature of a small lobular breast carcinoma in a myoid hamartoma [2].

Macroscopically, myoid hamartomas usually present as firm, mobile, well-delineated tumours.

The pathogenesis has not yet been completely elucidated. The only muscle cells present in the breast outside the stroma are those of the erector muscle of the nipple. Hypotheses on the pathogenesis of myoid hamartomas include a metaplastic process emanating from the myoepithelium, a myofibroblastic origin or an origin from local vascular walls. Another theory has proposed a possible differentiation out of ordinary stromal cells, which can differentiate into fat cells, cartilage cells, bone or smooth muscle cells [3].

In the literature, the radiological description of myoid hamartoma of the breast was that of a smooth, delineated, homogeneous, hyperdense or isodense focal nodule with no associated calcifications.

In the case presented here, the myoid hamartoma presented as a largely uncircumscribed lesion with progressive growth over the 6-month period prior to punch biopsy, which became increasingly hyperdense with calcifications on mammography. Sonography showed focal findings with uncircumscribed margins, a hy-

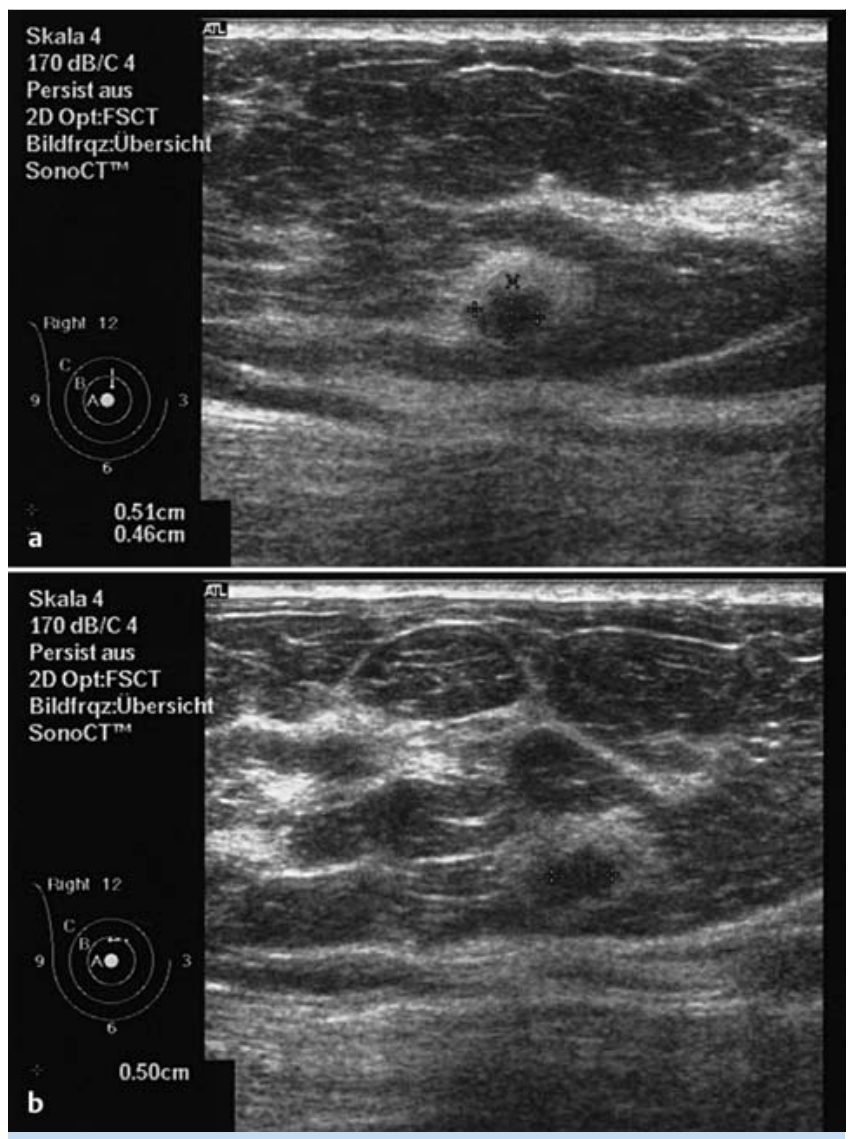

Fig. $\mathbf{2}$ and $\mathbf{b}$ Ultrasound images of the same lesion show a focal finding with an uncircumscribed margin and a diameter of $1.0 \times 0.9 \mathrm{~cm}$, a central hypoechoic area measuring $0.5 \times 0.5 \mathrm{~cm}$, and an unusually broad hyperreflexive border peripherally (BI-RADS 4). poechoic centre and an unusually broad hyperreflexive border peripherally.

The therapy of choice is excision biopsy with clear margins and this was also done in the present case, confirming the diagnosis made by punch biopsy. No further adjuvant therapy was required. The cause of recurrence of benign myoid hamartoma is unclear [4], as is the reason for its progressive growth. A possible hypothesis is a growth stimulation of the smooth muscle cells due to cycle-dependent changes in glandular breast tissue, although with 2 exceptions ( 37 years and 50 years, present case) the few cases (8) reported in the literature were older than 60 years and were post-menopausal without hormone substitution. Postoperatively we recommend regular annual follow-ups with mammography and sonography.

\section{Introduction to Cases 2 and 3}

$\nabla$

Capillary hemangiomas are rare vascular neoplasms, also called "strawberry marks". These benign anomalies occur predominantly in infancy and primarily affect the face and neck but they can also appear in the central nervous system. They commonly take the form of a flat or slightly elevated circumscribed tumour with an ample blood supply [5].

It is first necessary to differentiate hemangiomas ranging in size from a few millimetres to a few centimetres and composed of 


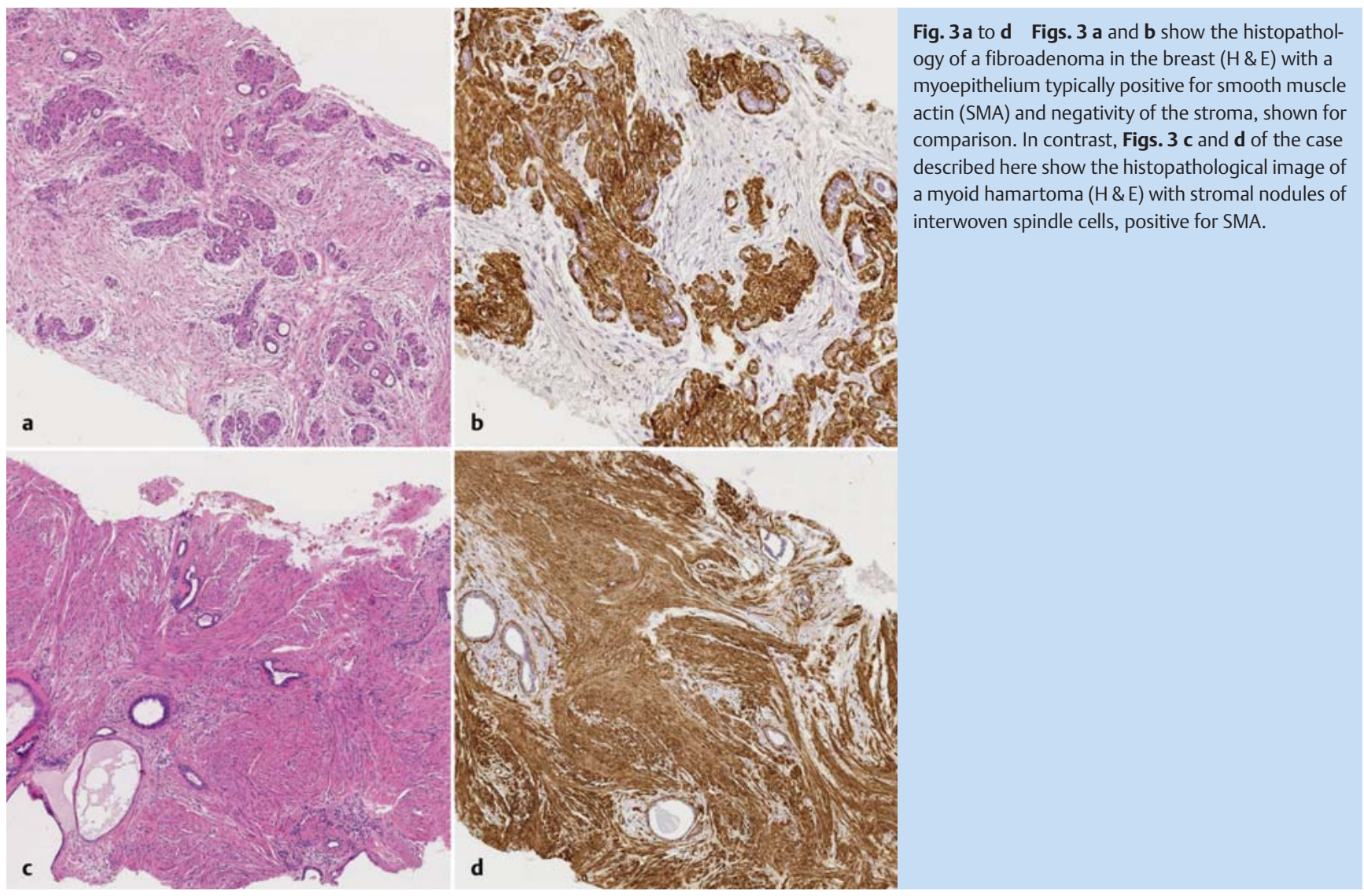

narrow, closely spaced capillaries from the larger cavernous hemangiomas, although the former may often merge into the latter. Capillary hemangiomas of the breast are rare and they are usually clinically inapparent, while cavernous hemangiomas described in the literature may reach a size where they can be palpated [6]. Mammographically they commonly present as a sharply circumscribed, oval lesion which appears only slightly denser than the parenchyma of regular mammary glands. Sonographic images usually show a circumscribed, sharply delineated, oval, hyperechoic, complex tissue structure abnormality [7].

We present here the rare finding of two local, subcutaneous, capillary hemangiomas of the breast, diagnosed in adult women.

\section{Description of Case 2}

A 66-year-old asymptomatic woman presented to our Centre as part of an early screening programme. She had a known familial history of cancer (mother and aunt) and a secondary diagnosis of rheumatoid arthritis.

Palpation and inspection of the breast and axillae were unremarkable.

Digital mammography showed the presence of a smooth, circumscribed, subcutaneous focal lesion in the left breast in the 1 o'clock position at $5 \mathrm{~cm}$ distant to the nipple with a diameter of $4 \times 4 \times 4 \mathrm{~mm}$, classified as BI-RADS4 ( Fig. 4 a, detail). The lesion was new and had appeared since the last examination one year previously.

Sonographic imaging of the lesion showed a circumscribed, sharply delineated, hyperechoic lesion $(4 \times 4 \times 4 \mathrm{~mm})$, with individual hypoechoic areas, located subcutaneously (Fig. $\$ 4$ b), and duplex sonography showed increased perfusion of the area (๑ Fig. 4c).

Additional shear wave elastography showed a relatively soft lesion with a medium $\mathrm{kPa}$ value of 14.7 and a maximum $\mathrm{kPa}$ value of 17.2, resulting in an elasticity ratio of 1.1 , which supported the conjecture of a benign lesion ( $\bullet$ Fig. 4 d).

Ultrasound-controlled punch biopsy was done to confirm the assumed benignity of the new solid nodule. Biopsy was performed without complications, and 4 cylindrical tissue samples were removed for assessment. Histopathological investigation resulted in a diagnosis of capillary hemangioma. (The small proliferations showed a typical covering of endothelial cells and no evidence of enlarged, atypical or hobnail arrangement of cells in the core. Immunohistochemically the formations were clearly positive for CD31 and negative for D2-40.) B classification was B2.

In the final assessment the nodule was classified as BI-RADS 2, and sonographic follow-up at 6 months after the procedure was recommended in accordance with S3 guidelines. Follow-up after 6 months showed stable findings.

\section{Description of Case 3}

$\nabla$

This 2nd patient presented to our Centre for further clarification. Her previous history included breast-conserving therapy after a diagnosis of breast cancer in the left breast in 2005 which included adjuvant endocrine therapy with an aromatase blocker. The patient had no symptoms in the breast. An elastic, flat, smooth lump with a diameter of $12 \mathrm{~mm}$ was newly palpated in the right breast at the 6 o'clock position at $10 \mathrm{~cm}$ from the nipple; otherwise all findings were clinically unremarkable. 

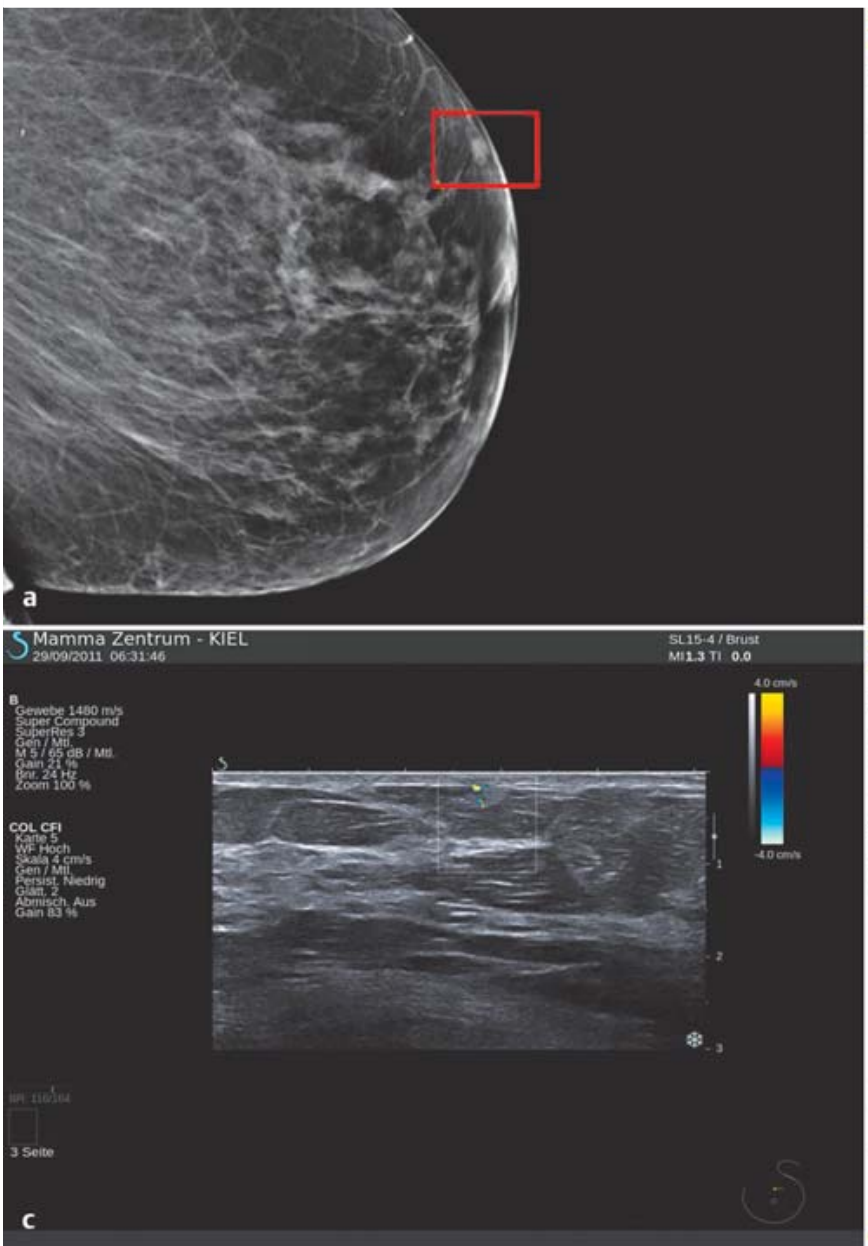

Fig. 4 a to d a Dig. mammogram of the left breast (MLO projection, detail) showing a focal finding in the 1 o'clock position, $5 \mathrm{~cm}$ from the nipple, with smooth edges, located subcutaneously, and measuring $4 \times 4 \times 4 \mathrm{~mm}$ (indicated by small squares, BI-RADS 4). $\mathbf{b}$ The sonographic image of the same lesion shows a circumscribed, sharply delineated, hyperechoic nodule

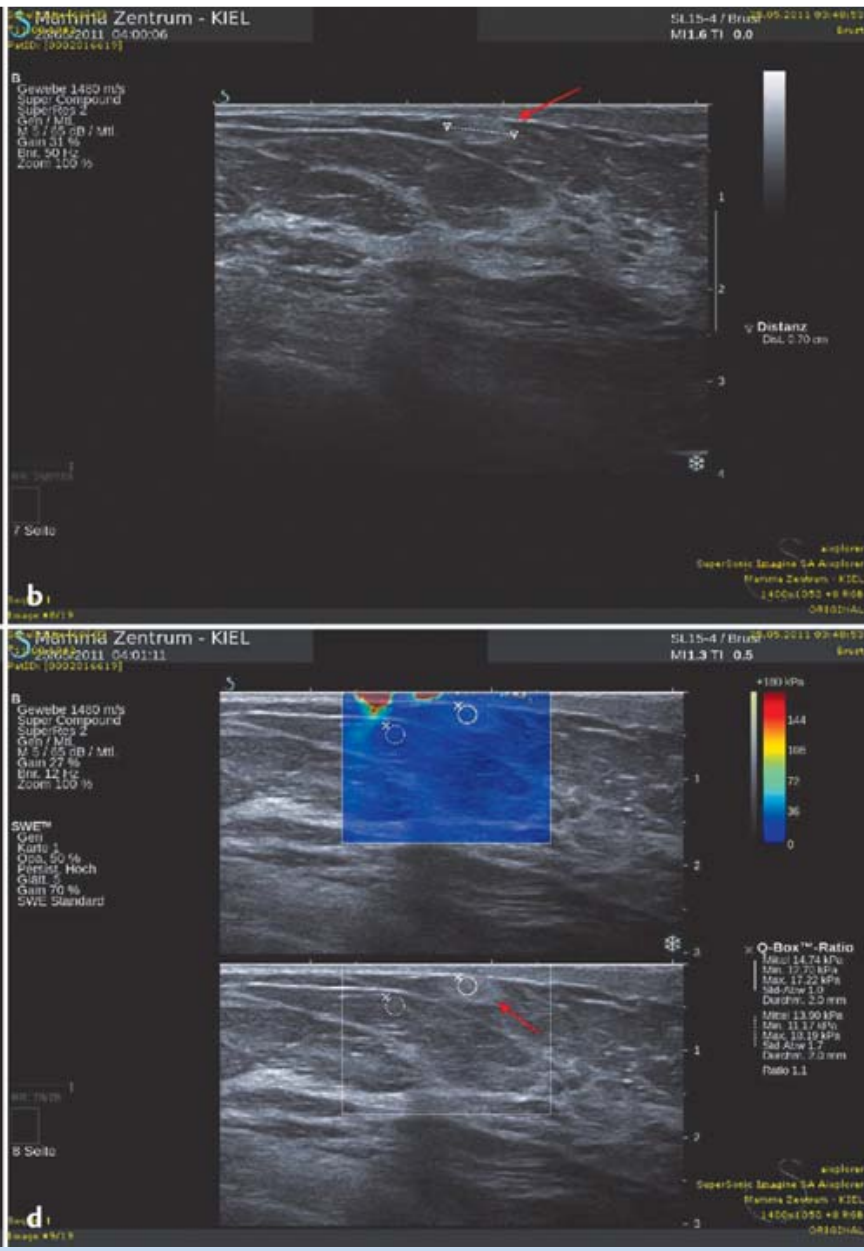

$(4 \times 4 \times 4 \mathrm{~mm})$ with individual hypoechoic areas, located subcutaneously (arrow). c Duplex sonography demonstrates increased perfusion. $\mathbf{d}$ Additional shear wave elastography shows a relatively soft lesion (blue pattern) with a medium $\mathrm{kPa}$ value of 14.7 and a maximum $\mathrm{kPa}$ value of 17.2 , resulting in an elasticity ratio of 1.1 .
Digital mammography showed a smooth, circumscribed, focal lesion in the right breast with a diameter of $1.3 \times 0.8 \times 1.3 \mathrm{~cm}$ in the six o'clock position (BI-RADS 4, $\odot$ Fig. 5 a, detail), $12 \mathrm{~cm}$ from the nipple. Additional findings in the right breast included progressive microcalcifications in the upper half of the breast approximately in the 12 o'clock position over an area with a total size of $2 \mathrm{~cm}$. The individual elements were partly dystrophic, partly coarsely granular. The nodule was classified as BI-RADS 4 (diagnosis of adenosis confirmed by vacuum biopsy, B2).

Sonographic imaging of the lesion showed a hypoechogenic focus with intermediate signal intensity, a predominantly smooth border, slight macrolobulation with dorsally undifferentiated echogenicity, a diameter of $1.3 \times 0.5 \times 1.1 \mathrm{~cm}$ ( $\mathbf{F i g} . \mathbf{5} \mathbf{b}$ ) and increased perfusion ( $\bullet$ Fig. 5 c). Shear wave elastography established a maximum value of $22.5 \mathrm{kPa}$ and a median value of $10.9 \mathrm{kPa}$, giving an elasticity ratio of 1.4 ( $\bullet$ Abb. $5 \mathrm{~d}$ ). Ultrasoundcontrolled punch biopsy was performed without complications, and a diagnosis was made, based on histopathological findings, of a capillary hemangioma (B classification: B2). Ultrasound follow-up of this 2nd case showed no change at 6 months after biopsy.

\section{Discussion of Cases 2 and 3}

Vascular tumours are rare entities of the breast. It is important to distinguish between hemangiomas and angiosarcomas. The cases described here presented with capillary hemangiomas, which can occur at every age.

Histologically, hemangiomas are benign vascular tumours. It is important to distinguish between capillary and cavernous hemangiomas, which depend on the vascular diameter [6]. Hemangiomas are differentiated into 4 types: perilobular, parenchymal, subcutaneous and venous hemangiomas.

As discussed in other case reports, the 4 subtypes are differentiated as follows: the most commonly occurring, perilobular hemangiomas are small, impalpable, and are usually found as microscopically small lesions in extralobular tissue, while parenchymal hemangiomas can also be found between the lobuli and have varying vascular diameters. Venous hemangiomas are vascular proliferations with very soft, thick vascular walls. Subcutaneous hemangiomas are found in subcutaneous adipose tissue ventral to the pectoralis major fascia and may either be palpable, as described here in Case 2, or clinically inapparent as in Case 1 [8]. 


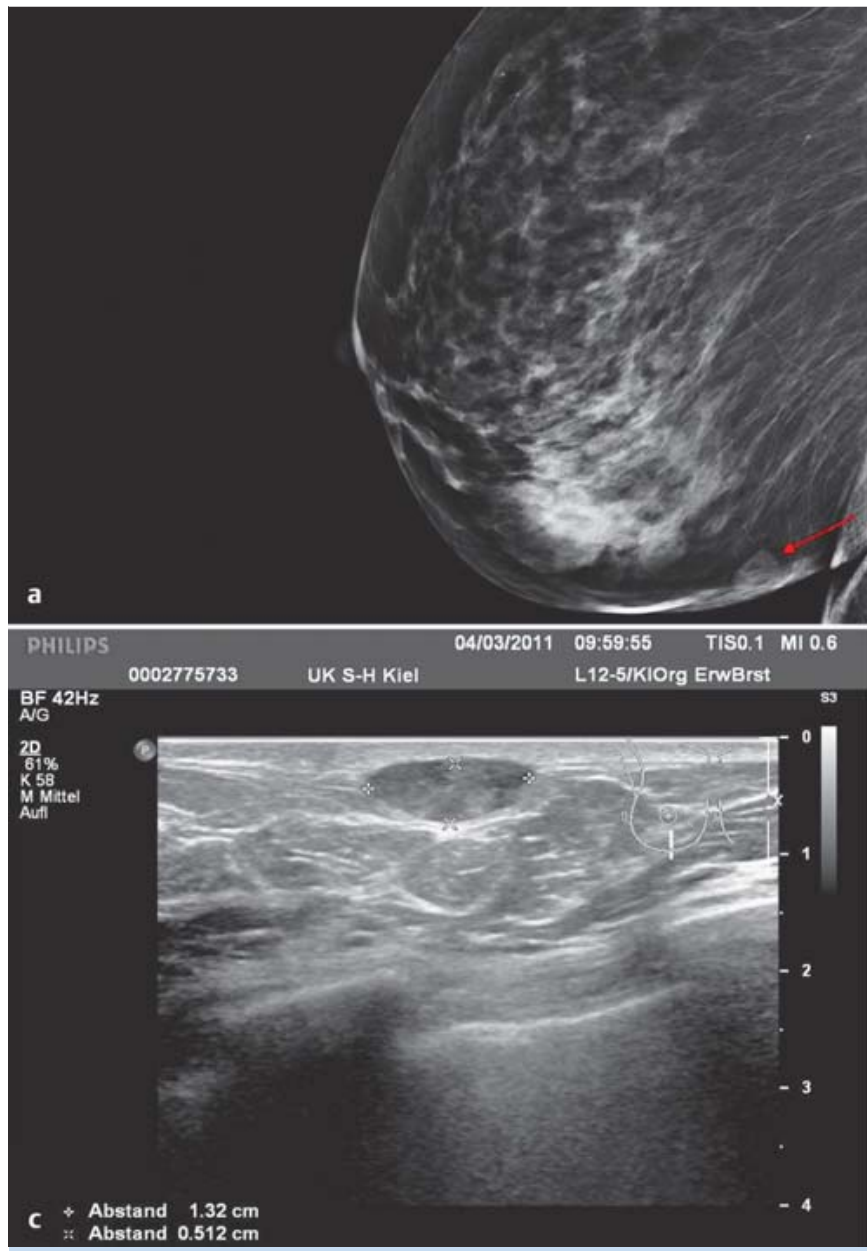

Fig. $\mathbf{5}$ a to $\mathbf{d}$ a Digital mammogram of the right breast (ML projection, detail) showing a smooth, circumscribed focal nodule (arrow) with a diameter of $1.3 \times 0.8 \times 1.3 \mathrm{~cm}$ in the 6 o'clock position (BI-RADS 4), $12 \mathrm{~cm}$ from the nipple. b High-resolution B-mode sonography image showing a hypoechogenic nodule with intermediate signal intensity, mainly smooth margins,

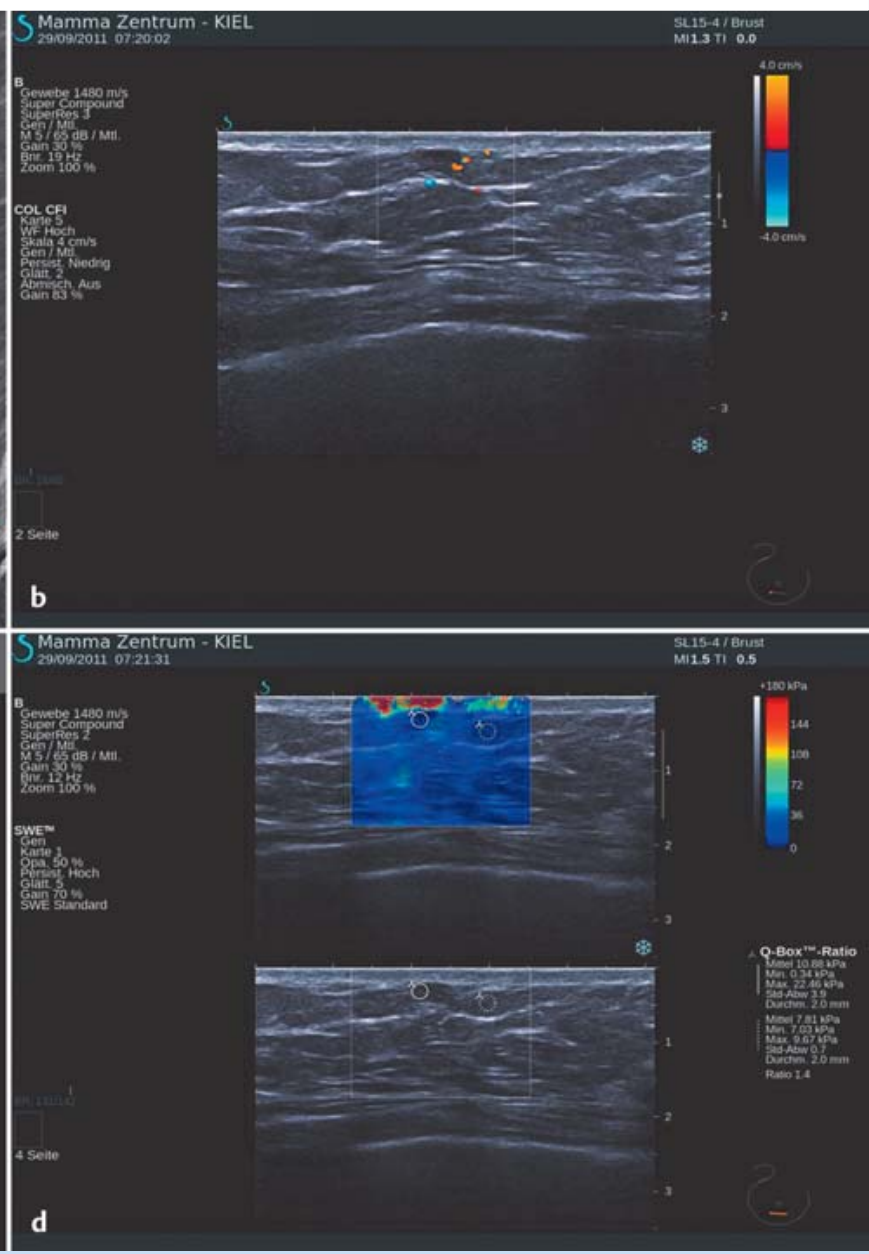

slight macrolobulation, dorsally undifferentiated echogenicity, and a diameter of $1.3 \times 0.5 \times 1.1 \mathrm{~cm}$. c Duplex sonography shows increased perfusion. d Shear wave elastography shows a maximum elasticity value of $22.5 \mathrm{kPa}$ (relatively soft tissue, blue pattern) and a medium value of $10.9 \mathrm{kPa}$, resulting in an elasticity ratio of 1.4 .
Some authors have recommended complete excision of subcutaneous hemangiomas, as ultimately it is difficult to differentiate them from angiosarcoma using imaging procedures or histopathology [7]. This particularly pertains to large findings, as a "sampling error" can occur with punch biopsy. In the cases described above, the small tumour size clearly pointed to a benign histology, so that the only recommendation was for sonographic follow-up 6 months after punch biopsy in accordance with S3 guidelines. Follow-up showed no changes in either case.

Alternatively, in the case of larger lesions, the further procedure could have included vacuum biopsy for minimally invasive clarification, as the larger biopsy sample size obtained with needle biopsy (needle sizes range from 8 to 12 gauge, depending on the manufacturer) results in a considerably lower rate of false negative findings. The literature gives a false negative rate of max. 1$1.4 \%$ for stereotactic vacuum-assisted biopsies [9]. Complete resection of tumours with diameters of up to $2 \mathrm{~cm}$ using ultrasound-controlled vacuum-assisted biopsy has been described in up to $86 \%$ of cases [10]. It is important to consider the location of the findings when making the diagnosis. In the cases described here, the lesions were located subcutaneously and vacuum-assisted biopsy would have involved a high risk of injury to the cutis.
In the literature, mammography images of hemangiomas commonly consist of smooth, oval shaped, partly macrolobulated nodules which are mainly described in terms of their parenchymal density. Associated microcalcifications are also possible but did not occur in the cases described here ( Figs. $4 \mathrm{a}$ and $\mathbf{5 a}$ ).

Sonographically, the findings are more heterogeneous: descriptions mostly consist of an oval shape with smooth edges; however findings can be either hyperechoic (Case 2, O Fig. 4b) or hypoechoic (Case 3, $\bullet$ Fig. 5c), making a diagnosis based on imaging alone difficult [7].

Thus, a definitive diagnosis can sometimes only be obtained using minimally invasive procedures such as ultrasound-controlled punch biopsy and ultrasound-controlled or stereotactic vacuumassisted biopsy. The differential diagnosis of a solid, newly occurring, hypoechogenic lesion must also consider the possibility of breast cancer, in addition to all known benign entities. The diagnosis of capillary hemangioma is rare in this context, as is the differential diagnosis of angiosarcoma. The latter occurs slightly more frequently as the result of previous radiation therapy of the breast or thoracic wall [11].

The differential diagnosis of a hyperechoic lesion found on ultrasound should always include hamartoma if the lesion's density on mammography is sufficiently high; the diagnosis can easily 
be verified by taking the patient's case history into account. The differential diagnosis should also include granular cell tumour, an extremely rare entity which, if confirmed histologically, requires total resection due to its potential for growth and risk of recurrence [12]. The diagnosis of hyperechoic lipoma or oil cyst can be made based on imaging procedures alone if the ultrasound image is combined with findings of adipose tissue on mammography.

Elastography has the potential to become a complementary diagnostic tool in addition to high-resolution ultrasound. Malignant breast tumours usually consist of tissue which is firmer than normal, healthy, mammary gland parenchyma. Sonography used to show elasticity can record the firmness of the investigated tissue, providing information for the diagnosis and differentiation of tumours. This is where elastography based on mechanical compression differs fundamentally from shear wave elastography, the most recent development in this field. Used as a complementary investigative tool, shear wave elastography is user independent, can be learnt quickly, and uses ultra-quick imaging. The technique is based on the use of shear acoustic waves which travel through tissue. The distortion of the shear waves is investigated and quantified using mathematical algorithms to give the investigator information about the tissue's firmness and elasticity. The technique is used to determine $\mathrm{kPa}$ (kilo Pascal) values for the investigated tissue. Malignant tissue usually has a $\mathrm{kPa}$ $>72$, although findings for malignant tissue can be relatively heterogeneous, more so than in benign nodules [13].

\section{Conclusions for General Practice}

In summary, the cases described here and the overview of the literature demonstrate the heterogeneity of myoid hamartomas and also of capillary hemangiomas in imaging diagnostics (mammography, high-resolution ultrasound, duplex sonography, shear wave elastography) and their differential diagnoses.

\section{Conflict of Interest}

$\nabla$

None.

\section{References}

1 Murugesan JR, Joglekar S, Valerio D et al. Myoid hamartoma of the breast: case report and review of the literature. Clin Breast Cancer 2006; 7: 345-346

2 Mathers ME, Shrimankar J. Lobular neoplasia within a myoid hamartoma of the breast. Breast J 2004; 10: 58-59

3 Magro G, Bisceglia M, Michal M et al. Spindle cell lipoma-like tumor, solitary fibrous tumor and myofibroblastoma of the breast: a clinicopathological analysis of 13 cases in favor of a unifying histogenetic concept. Virchows Arch 2002; 440: 249-260

4 Tse GM, Law BK, MaTK et al. Hamartoma of the breast: a clinicopathological review. J Clin Pathol 2002; 55: 951-954

5 Verma K, Verma KK. Infantile periocular haemangioma treated with two days in a week betamethasone oral mini pulse therapy. Indian J Pediatr 2001; 68: 355-356

$6 \mathrm{Kim} \mathrm{SM,} \mathrm{Kim} \mathrm{HH}$, Shin HJ et al. Cavernous haemangioma of the breast. Br J Radiol 2006; 79: 177-180

7 Mesurolle B, Sygal V, Lalonde L et al. Sonographic and mammographic appearances of breast hemangioma. Am J Roentgenol 2006; 191: 1722

8 Kawatra V, Lakshmikantha A, Dinghra KK et al. A rare coexistence of concurrent breast hemangioma with fibroadenoma: a case report. Cases J 2009; 15: 7005

9 Peter D, Grünhagen J, Wenke R et al. False-negative results after stereotactically guided vacuum biopsy. Eur Radiol 2007; 18: 177-182

10 Krainick-Strobel U, Huber B, Majer I et al. Complete extirpation of benign breast lesions with an ultrasound-guided vacuum biopsy system. Ultrasound Obstet Gynecol 2007; 29: 342-346

11 Nestle-Krämling C, Bölke E, Budach $W$ et al. Hemangiosarcoma after breast-conserving therapy of breast cancer: report of four cases with molecular genetic diagnosis and literature review. Strahlenther Onkol 2011; 187: 656-664

12 Filipovski V, Banev S, Janevska Vet al. Granular cell tumor of the breast: a case report and review of literature. Cases J 2009; 2: 8551

13 Berg W, Cosgrove DO, Doré CJ et al. Shear-wave elastography improves the specificity of breast US: the BE1 multinational study of 939 masses. Radiology 2012; 262: 435-449

Deutschsprachige Zusatzinformationen online abrufbar unter: www.thieme-connect.de/ejournals/toc/gebfra. 